City University of New York (CUNY)

CUNY Academic Works

2017

\title{
Assessment of Differences between Near-Surface Air and Soil Temperatures for Reliable Detection of High-Latitude Freeze and Thaw States
}

\author{
Farjana Shati \\ CUNY New York City College of Technology \\ Satya Prakash \\ CUNY New York City College of Technology \\ Hamid Norouzi \\ CUNY New York City College of Technology \\ Reginald Blake \\ CUNY New York City College of Technology
}

\section{How does access to this work benefit you? Let us know!}

More information about this work at: https://academicworks.cuny.edu/ny_pubs/204

Discover additional works at: https://academicworks.cuny.edu

This work is made publicly available by the City University of New York (CUNY).

Contact: AcademicWorks@cuny.edu 
Assessment of differences between near-surface air and soil temperatures for reliable detection of high-latitude freeze and thaw states

\author{
Farjana Shati, Satya Prakash*, Hamid Norouzi, and Reginald Blake \\ New York City College of Technology, \\ City University of New York, \\ Brooklyn, NY 11201, USA
}

*Corresponding author's email: sprakash@ citytech.cuny.edu

Cold Regions Science and Technology

Vol. 145, pp. 86-92, doi:10.1016/j.coldregions.2017.10.007 


\begin{abstract}
Near-surface air temperature and the underlying soil temperature are among the key components of the Earth's surface energy budget, and they are important variables for the comprehensive assessment of global climate change. Better understanding of the difference in magnitude between these two variables over highlatitude regions is also crucial for accurate detections of freeze and thaw (FT) states. However, these differences are not usually considered and included in current remote sensing-based FT detection algorithms. In this study, the difference between near-surface air temperature at the 2-meter height and soil temperature at the 5-centimeter depth is assessed using ground-based observations that span a three-year period from 2013 to 2015. Results show noticeable differences between air and soil temperatures over temporal scales that range from diurnal to seasonal. The study also suggests that the ground-based upper layer soil temperature may be a better surrogate than the near-surface air temperature for the reliable detection of FT states at high-latitudes. Furthermore, the results from this study are particularly useful for better understanding the surface energy budget that ultimately drives the land surface processes that are embedded within weather and climate models.
\end{abstract}

Keywords: Freeze and thaw states; Ground-based observations; Land surface emissivity; Near-surface air temperature; Soil temperature.

\title{
1. Introduction
}

Near-surface air temperature and soil temperature are among the key variables for the assessment of global climate change and surface energy budget (Zheng et al., 1993; Chudinova et al., 2006). These variables also control soil moisture content, which in turn plays a critical role in ecosystem conditions through the exchange of heat and water fluxes between the atmosphere and the land surface (Brown et al., 2000; Betts, 2009). Soil temperature is also crucial for agricultural practices and vegetation health (height and density), and it is influenced by geographic, climatic, and environmental features. Since in-situ observations of soil temperatures are rather sparse at the global scale, they can be estimated through the energy balance equation and empirical methods. However, the relationships among soil temperature, soil moisture, skin temperature and air 
temperature are still not adequately explored. These relationships are currently being copiously studied by the research community.

Although both air and soil temperatures have considerable differences, they are oftentimes used interchangeably for some specific applications and in algorithms used to detect high-latitude freeze and thaw (FT) states. Nearly one-third of the global land areas exhibit seasonal freezing and thawing transitions, and these transitions play vital roles in hydrological activities, vegetation dynamics, terrestrial carbon and methane budgets, and in land-atmosphere trace gas exchanges (Jin et al., 2009; Wu et al., 2011; Shahroudi and Rossow, 2014; Du et al., 2015). Accurate detection of regional FT states and their variability is also vital for several land surface process applications. Since groundobservations of FT states in boreal regions are generally sparse and inconsistent, the effective monitoring of FT processes in these regions is difficult. However, remote sensing applications in the active and passive microwave bands have produced reliable FT monitoring over this region (Zhang and Armstrong, 2001; Podest et al., 2014). In the recent decade, several remote sensing-based FT detection algorithms have been developed. For instance, long-term (starting from 1979) daily FT records at the global scale (Kim et al., 2011, 2017) were developed from passive microwave brightness temperatures. Some of these algorithms use ground-based near-surface air temperature observations as reference, while others use upper layer soil temperature as reference. The community, therefore, has yet to reach consensus about which of the two temperatures (or some combination of both) to use in FT algorithms, and the lack of agreed consistency on this issue may have far reaching impacts not only on the detection of FT states, but also on the myriad of other geophysical phenomena that rely on these interactions.

A main objective, therefore, of this study is to assess the differences between insitu near-surface air temperatures and soil temperatures over selected stations of North America, a region having appreciably good networks of simultaneous air and soil temperature observations. The study will also make the case that upper layer soil temperature, and not near-surface air temperature, should be used as the reference temperature in effective FT state detection algorithms and in the comprehensive study of related soil characteristics. 


\section{Data and Methods}

The relevant in-situ near-surface air temperature (at $2 \mathrm{~m}$ ), soil temperature (at $5 \mathrm{~cm}$ ), and snow depth data were obtained from the Snow Telemetry (SNOTEL) stations maintained by the National Resources Conservation Service and the National Water Climate Center (Serreze et al., 1999). Hourly data sets were collected over the span of a three-year period from 2013 to 2015. Several SNOTEL stations were used to investigate the differences between both temperatures for distinct weather conditions (e.g., snow versus no-snow). However, for brevity, only the results from six stations are shown and discussed in this study. The six stations were chosen so that they cover a wide range of geographic, topographic, and land cover features (e.g., Fig. 1). The International Geosphere-Biosphere Programme (IGBP) global land cover type product from the MODIS (e.g., MCD12C1 version 051) available at $0.05^{\circ}$ spatial resolution (Friedl et al., 2010) is used to determine the vegetation type of the selected stations. Additionally, the land surface emissivity estimates, recently developed using the Advanced Microwave Scanning Radiometer - 2 (AMSR2), were used for the year 2015. These instantaneous land surface emissivity estimates are available at $0.25^{\circ}$ spatial resolution (Prakash et al., 2016). To accurately compute the land surface emissivity from AMSR2 brightness temperatures at seven frequency channels, near simultaneous infrared-based land surface temperature, and profiles of air temperature and humidity were used. Furthermore, the discrepancy between the diurnal cycles of passive microwave brightness temperatures and infrared-based land surface temperature was minimized using a suitable statistical method (Norouzi et al., 2012, 2015; Prakash et al., 2016). It was recently demonstrated (Prakash et al., 2017) that due to its direct interactions with soil characteristics, remote sensing-based microwave land surface emissivity detects FT states better than brightness temperature.

Two specific times centered at 1:30 Local Standard Time (LST) and 13:30 LST were chosen for the analysis, because they were comparable to the AMSR2 equatorial crossing times. The linear average of 1:00 LST and 2:00 LST observations were calculated to get observations at 1:30 LST (nighttime/descending), and the linear average of 13:00 LST and 14:00 LST (the linear interpolation used does not affect the results considerably) were used to obtain observations of snow depth, air and soil temperatures 
at 13:30 LST (daytime/ascending). The differences between both parameters (e.g., soil and air temperatures) were studied for two different soil conditions, i.e., freeze and thaw states. These differences were computed for soil frozen states with soil temperatures less than or equal to $0^{\circ} \mathrm{C}$ and simultaneously for air temperatures greater than $0^{\circ} \mathrm{C}$; they were also computed for soil thawed states with soil temperatures greater than $0^{\circ} \mathrm{C}$ and simultaneously for air temperatures less than or equal to $0^{\circ} \mathrm{C}$. These differences show the uncertainty in FT state detection due to the use of near-surface air temperature rather than the use of upper soil temperature. The seasonal and diurnal variations of the differences between both temperatures were also examined in this study.

\section{Results and Discussions}

Fig. 2 shows the three-year mean and standard deviation of the near-surface air temperature and the upper layer soil temperature during day and night times for the six selected stations. The three Alaskan stations show mean air temperature values less than $0^{\circ} \mathrm{C}$. Noticeable differences between the soil and the air temperatures are observed over all six stations. The differences between daytime and nighttime temperatures are higher for air than for soil. As expected, lower temperatures during nighttime as compared to daytime are observed from both variables. These differences are associated with the diurnal variation of surface energy flux. Typically, surface energy balance is positive when net shortwave absorption exceeds net longwave loss during the daytime. The surface emits energy during daytime, while it needs more energy at night due to no incoming solar shortwave radiation; this results in downward latent and sensible heat flux from the atmosphere to the surface. Air temperature exhibits larger magnitude of standard deviation as compared to the soil temperature. During the daytime, standard deviation is larger than nighttime in both air and soil temperatures.

In order to investigate the differences between air and soil temperatures at the daily timescale, time-series analysis was performed. Fig. 3 shows daily air and soil temperatures and their differences during both day and nighttime for the three-year period for a SNOTEL station located at Colorado. Higher temperatures during the summer and lower temperatures during the winter for both air and soil correlate well with snowfall amounts. However, notable differences between both temperatures can be seen. These 
difference are larger during daytime than nighttime. Air temperatures show larger day-today variability due to insolation and weather conditions, while soil temperatures essentially vary rather slowly. Soil properties also change at slower rates due to the indirect effect of local weather conditions. The differences between these two temperatures also vary with the seasonal snow cover. The snow cover works as an effective thermal insulator due to low thermal conductivity; however, the overall impact of snow cover on the ground thermal regime depends on the duration, accumulation and melting processes of the seasonal snow cover (Zhang, 2005; Cook et al., 2008; Park et al., 2014). Hence, the variations in near-surface air temperature alone could not explain the soil temperature variations. Additionally, the presence and absence of snow cover strongly impact the surface net radiation flux and thereby have critical climate implications (Betts, 2009). These results indicate that the upper layer soil temperature may be a more stable and effective parameter to use in FT studies than the near-surface air temperature.

A substantial portion of the global land area exhibits seasonal FT cycles, and the transitions between freeze and thaw states depend on the magnitude and the direction of the heat energy flux and on the corresponding change in seasonal and diurnal temperatures. There are a substantial number of days observed for each station in which soil temperatures show freezing, but air temperatures show thawing, and vice-versa. Fig. 4 presents the frequency of occurrence of such events during day and nighttime separately. In general, air temperature could not detect soil freezing during about $5 \%$ of daytime and more than $11 \%$ of nighttime. Similarly, air temperature could not detect soil thawing during about $7 \%$ of daytime and about $13 \%$ of nighttime. Hence, the use of air temperature for soil FT detection might lead to larger uncertainty. The percentage contributions of each month in these differences are illustrated in Fig. 5. January to May contributes most of the cases when the soil is frozen, but it goes undetected by the air temperature. April, and October to December months contribute most of the cases when soil is thawed, while simultaneously the air temperature indicates frozen. The analysis also shows a pronounced seasonal variation in the differences between air and soil temperatures and their corresponding FT signatures. 
Fig. 6 shows the diurnal variations of hourly air and soil temperatures over a SNOTEL site of Alaska for the year 2015. Three months - January, August and October were selected for this analysis as they correspond to frozen, thawed, and transition months. Although both air and soil temperatures exhibit similar kinds of variability, the range in magnitude is larger for air temperatures than for soil temperatures. It is also noted that due to the averaging of hourly data for a month, some fine features of the diurnal cycle are not seen here, even though both air and soil temperatures show differences in magnitude.

Passive microwave remote sensing has become a reliable tool for studying the FT states at global and regional scales. Land surface emissivity estimates are developed to minimize atmospheric effects, and are, therefore, assumed to be better representatives of land surface and sub-surface characteristics than brightness temperatures. An instantaneous global land surface emissivity product from the AMSR2 observations was recently developed utilizing an improved algorithm and near-simultaneous ancillary data sets (Prakash et al., 2016). The potential of this land emissivity product (difference between lower and higher frequency channel emissivity estimates) for reliable FT state detection was also demonstrated over the high-latitude regions (Prakash et al., 2017). Fig. 7 presents the mean monthly AMSR2 land emissivity differences between 6 and $89 \mathrm{GHz}$ at horizontal polarization over the Northern high-latitude regions (north of $35^{\circ} \mathrm{N}$ ) for January, August and October of 2015. The monthly composites for ascending and descending overpasses of AMSR2 are presented separately. Larger positive differences in emissivity indicate the frozen state, which is prominent during the month of January. Similarly, lower magnitude of differences (e.g., negative) in emissivity refers to thawed state as observed during the month of August. The transition from thaw to freeze state is prominent during the month of October, which is qualitatively captured by the emissivity difference. Hence, the use of passive microwave land emissivity estimates along with ground-based upper layer soil temperature has great potential for global soil FT detection to improve the understanding of the ecosystem.

The global scale in-situ observations of soil temperatures are relatively sparse and inconsistent compared to the corresponding air temperature and this constrains the applications of soil temperature usage. Additionally, remote sensing of soil temperatures 
is challenging and no satellite-based product is currently available to do so. Satellitebased estimates are available for skin temperatures, but not for soil layers (e.g., at $5 \mathrm{~cm}$ ) except in some reanalysis products. The scatter plots between both air and soil temperatures for the three-year period (2013-2015) at the six SNOTEL stations for day and nighttime are shown in Fig. 8. The plots clearly show that a non-linear relationship, dependent on day and night, exists between near-surface air and upper layer soil temperatures. The relationship between both temperatures was also studied in the past (e.g., Zheng et al., 1993; Brown et al., 2000; Chudinova et al., 2006). The seasonal snow cover, having higher albedo, lower thermal conductivity, higher latent heat and higher emissivity, introduces complexity in their relationship over the high-latitude regions (Zhang, 2005; Cook et al., 2008). The timing, duration, accumulation and melting processes of the snow are also crucial for the relationship between near-surface air temperature and soil temperature. Hence, estimation of upper layer soil temperature from near-surface air temperature by properly taking seasonal snow cover into account (especially over the high-latitude regions) would certainly enhance the global scale applicability of upper layer soil temperature. During the freeze-thaw transition periods, snow on the ground makes a layer that does not eventually allow the soil to be frozen/thawed despite cold/warm air temperatures. It is imperative, therefore, and there is a need, that the research community develops an algorithm that estimates upper layer soil temperature from the Earth-observation satellites so as to more accurately and realistically study global soil characteristics, particularly for several critical applications.

\section{Conclusion}

The differences between near-surface air temperatures and upper layer soil temperatures were assessed over North America. The analysis was done using six arbitrarily chosen SNOTEL observations for 2013-2015. Near-surface air temperatures showed larger variability than upper layer soil temperatures. In general, the differences between air and soil temperatures were larger during daytime than nighttime. There were notable differences between air and soil temperatures, which varied diurnally as well as seasonally. The seasonal snow cover also plays a crucial role in the relationship. The passive microwave land emissivity estimates support the suggestion that soil 
temperatures may represent soil characteristics more realistically than air temperatures do and, therefore, should be considered as the reference data for FT state detection. Moreover, both air and soil temperatures showed a time-dependent, non-linear relationship with each other. The study also showed that upper layer soil temperatures are more sensitive than near-surface air temperatures to soil characteristics, and that the use of upper layer soil temperature along with satellite-based land emissivity estimates may essentially provide more accurate soil FT detection analyses.

Acknowledgements: This study was supported by the National Science Foundation (NSF) Research Experiences for Undergraduates (REU) under Grant 1560050 and by the Department of Defense (DoD) Army Research Office (ARO) under Grant W911NF-151-0070. The statements contained within the manuscript are not the opinions of the funding agencies or the U.S. government, but reflect the authors' opinions. The authors would also like to acknowledge Dr. W. B. Rossow for helpful discussions, and the editor and anonymous reviewers for constructive comments.

\section{References}

Betts, A., 2009: Land-surface-atmosphere coupling in observations and models, $J$. Adv. Model. Earth Syst., 1, 4, doi:10.3894/JAMES.2009.1.4.

Brown, S. E., K. S. Pregitzer, D. D. Reed, and A. J. Burton, 2000: Predicting daily mean soil temperature from daily mean air temperature in four northern hardwood forest stands, Forest Sci., 46, 297-301.

Chudinova, S. M., O. W. Frauenfeld, R. G. Barry, T. Zhang, and V. A. Sorokovikov, 2006: Relationship between air and soil temperature trends and periodicities in the permafrost regions of Russia, J. Geophys. Res., 111, F02008, doi:10.1029/2005JF000342.

Cook, B. I., G. B. Bonan, S. Levis, and H. E. Epstein, 2008: The thermoinsulation effect of snow cover within a climate model, Clim. Dyn., 31, 107-124, doi:10.1007/s00382-0070341-y. 
Du, J., J. S. Kimball, M. Azarderakhsh, R. S. Dunbar, M. Moghaddam, and K. C. McDonald, 2015: Classification of Alaska spring thaw characteristics using satellite Lband radar remote sensing, IEEE Trans. Geosci. Remote Sens., 53, 542-556, doi:10.1109/TGRS.2014.2325409.

Friedl, M. A., D. Sulla-Menashe, B. Tan, A. Schneider, N. Ramankutty, A. Sibley, and X. Huang, 2010: MODIS Collection 5 global land cover: Algorithm refinements and characterization of new datasets, Remote Sens. Environ., 114, 168-182, doi:10.1016/j.rse.2009.08.016.

Jin, R., X. Li, and T. Che, 2009: A decision tree algorithm for surface soil freeze/thaw classification over China using SSM/I brightness temperature, Remote Sens. Environ., 113, 2651-2660, doi:10.1016/j.res.2009.08.003.

Kim, Y., J. S. Kimball, K. C. McDonald, and J. Glassy, 2011: Developing a global data record of daily landscape freeze/thaw status using satellite passive microwave remote sensing, IEEE Trans. Geosci. Remote Sens., 49, 949-960, doi:10.1109/TGRS.2010.2070515.

Kim, Y., J. S. Kimball, J. Glassy, and J. Du, 2017: An extended global Earth system data record on daily landscape freeze-thaw status determined from satellite passive microwave remote sensing, Earth Syst. Sci. Data, 9, 133-147, doi:10.5194/essd-9-133-2017.

Norouzi, H., W. Rossow, M. Temimi, C. Prigent, M. Azarderakhsh, S. Boukabara, and R. Khanbilvardi, 2012: Using microwave brightness temperature diurnal cycle to improve emissivity retrievals over land, Remote Sens. Environ., 123, 470-482, doi:10.1016/j.rse.2012.04.015.

Norouzi, H., M. Temimi, A. AghaKouchak, M. Azarderakhsh, R. Khanbilvardi, G. Shields, and K. Tesfagiorgis, 2015: Inferring land surface parameters from the diurnal 
variability of microwave and infrared temperatures, Phys. Chem. Earth, 83-84, 28-35, doi:10.1016/j.pce.2015.01.007.

Park, H., A. B. Sherstiukov, A. N. Fedorov, I. V. Polyakov, and J. E. Walsh, 2014: An observation-based assessment of the influences of air temperature and snow depth on soil temperature in Russia, Environ. Res. Lett., 9, 064026, doi:10.1088/17489326/9/6/064026.

Podest, E., K. C. McDonald, and J. S. Kimball, 2014: Multisensor microwave sensitivity to freeze/thaw dynamics across a complex boreal landscape, IEEE Trans. Geosci. Remote Sens., 52, 6818-6828, doi:10.1109/TGRS.2014.2303635.

Prakash, S., H. Norouzi, M. Azarderakhsh, R. Blake, and K. Tesfagiorgis, 2016: Global land surface emissivity estimation from AMSR2 observations, IEEE Geosci. Remote Sens. Lett., 13, 1270-1274, doi:10.1109/LGRS.2016.2581140

Prakash, S., H. Norouzi, M. Azarderakhsh, R. Blake, and R. Khanbilvardi, 2017: Potential of satellite-based land emissivity estimates for the detection of high-latitude freeze and thaw states, Geophys. Res. Lett., 44, 2336-2342, doi:10.1002/2017GL072560.

Serreze, M. C., M. P. Clark, R. L. Armstrong, D. A. McGinnis, and R. S. Pulwarty, 1999: Characteristics of the western United States snowpack from snowpack telemetry (SNOTEL) data, Water Resour. Res., 35, 2145-2160, doi:10.1029/1999WR900090.

Shahroudi, N., and W. Rossow, 2014: Using land surface microwave emissivities to isolate the signature of snow on different surface types, Remote Sens. Environ., 152, 638653, doi:10.1016/j.rse.2014.07.008.

Wu, T., Q. Wang, L. Zhao, O. Batkhishig, and M. Watanabe, 2011: Observed trends in surface freezing/thawing index over the period 1987-2005 in Mongolia, Cold Reg. Sci. Technol., 69, 105-111, doi:10.1016/j.coldregions.2011.07.003. 
Zhang, T., and R. L. Armstrong, 2001: Soil freeze/thaw cycles over snow-free land detected by passive microwave remote sensing, Geophys. Res. Lett., 28, 763-766, doi:10.1029/2000GL011952.

Zhang, T., 2005: Influence of the seasonal snow cover on the ground thermal regime: An overview, Rev. Geophys., 43, RG4002, doi:10.1029/2004RG000157.

Zheng, D., E. R. Hunt Jr., and S. W. Running, 1993: A daily soil temperature model based on air temperature and precipitation for continental applications, Clim. Res., 2, 183-191.
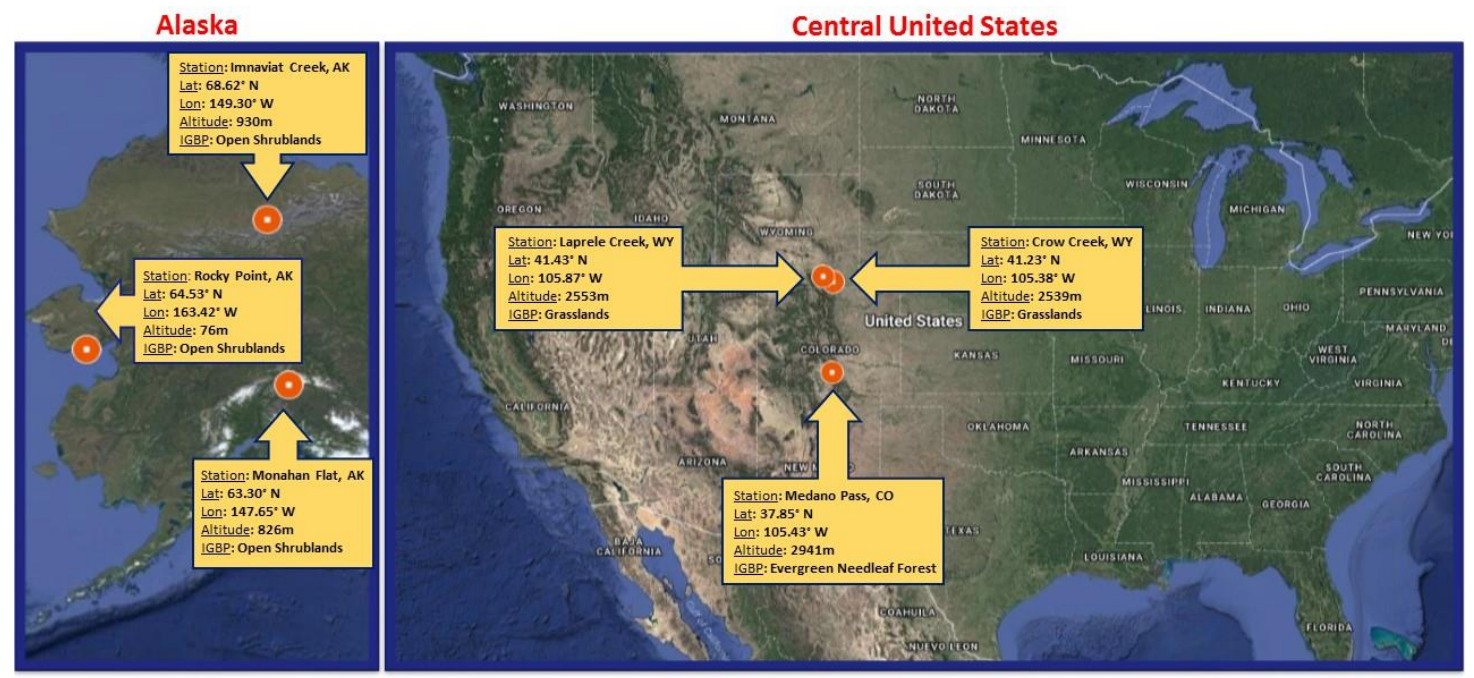

Fig. 1 Location of six selected SNOTEL stations considered in this study. Altitude and IGBP land cover type are also provided for each station. 

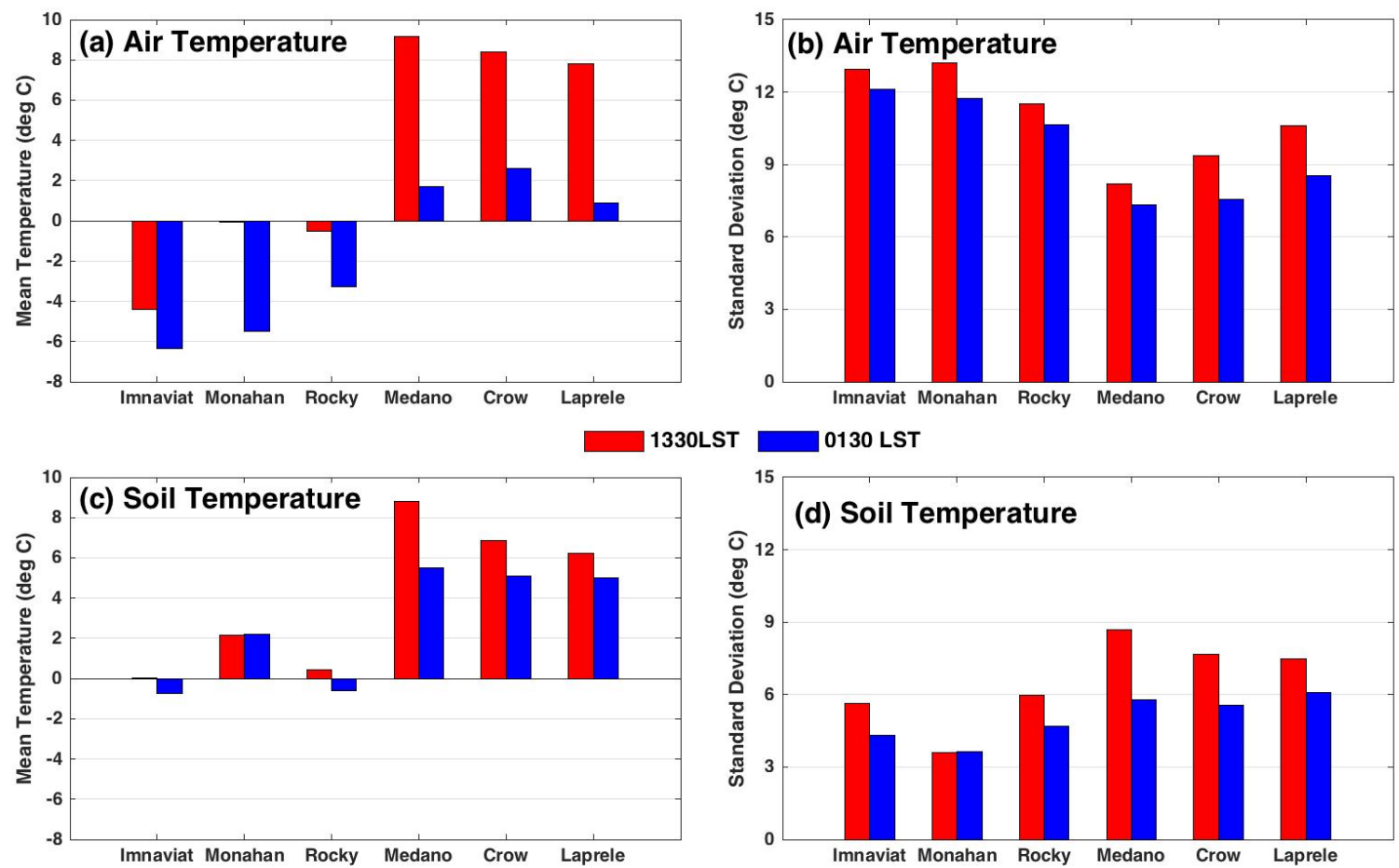

Fig. 2 Mean and standard deviation of daily air temperature and soil temperature over six SNOTEL stations for 0130 and 1330 LST for the period of 2013-2015. 
(a) Day (1330 LST)

Medano Pass, Colorado

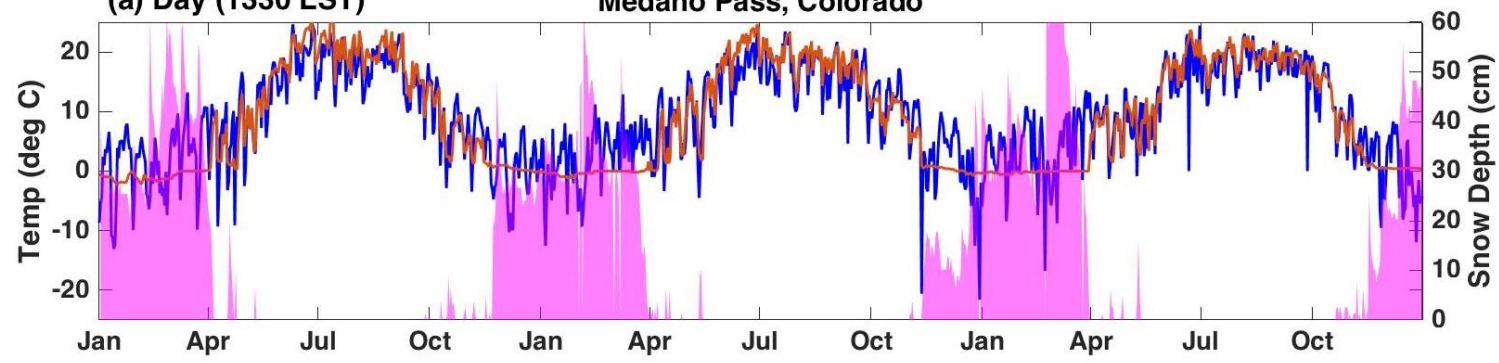

(b) Night (0130 LST)

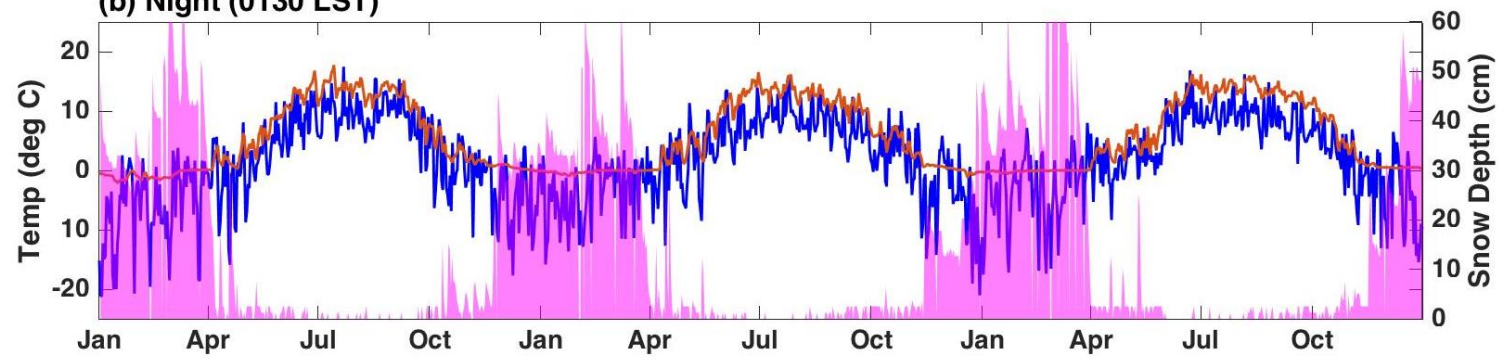

(c) Temperature Difference

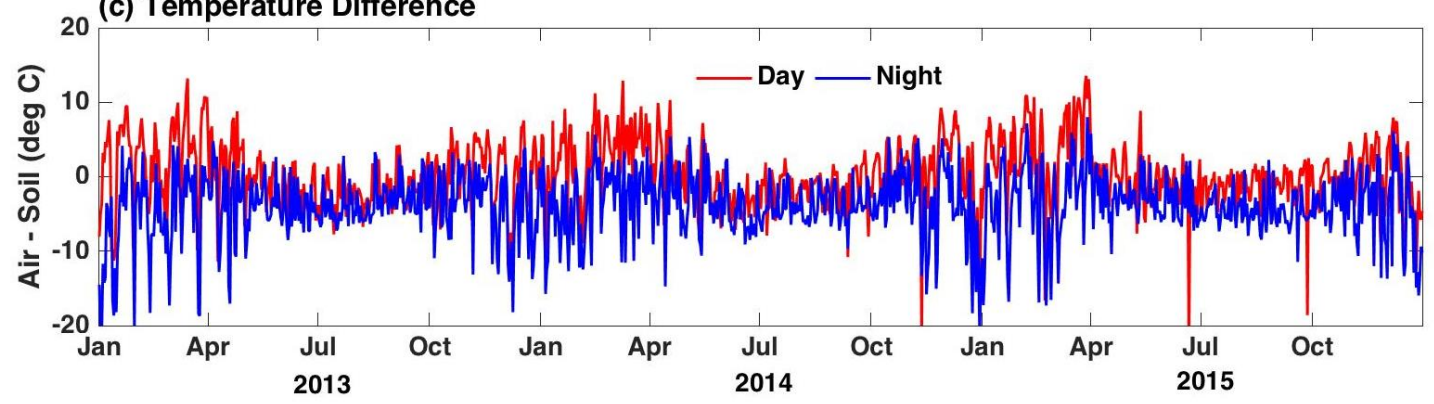

Fig. 3 Time-series of daily (a) daytime and (b) nighttime near surface air temperature and soil temperature, and (c) their differences over a SNOTEL station for a three-year period (2013-2015). The shaded area in Fig. 3(a-b) represents the snow depth. 

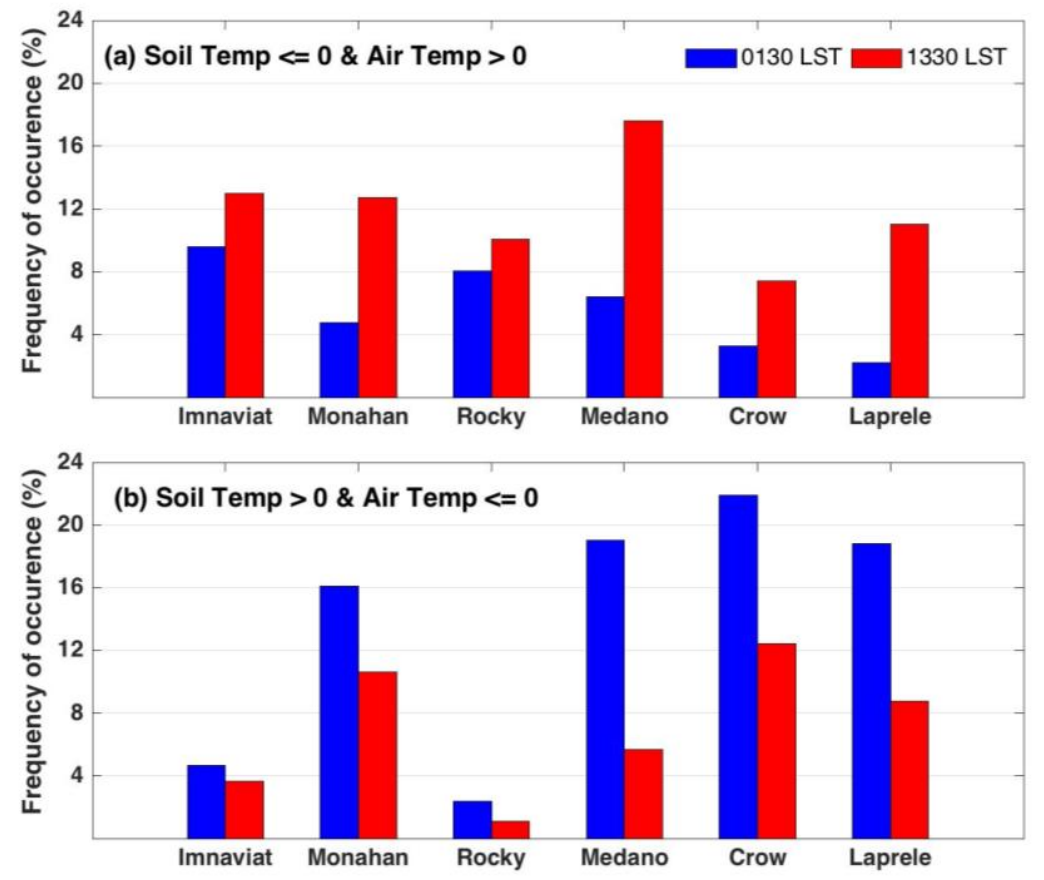

Fig. 4 Difference between air temperature and soil temperature over six SNOTEL stations under two distinct cases corresponding to soil freeze and thaw states.
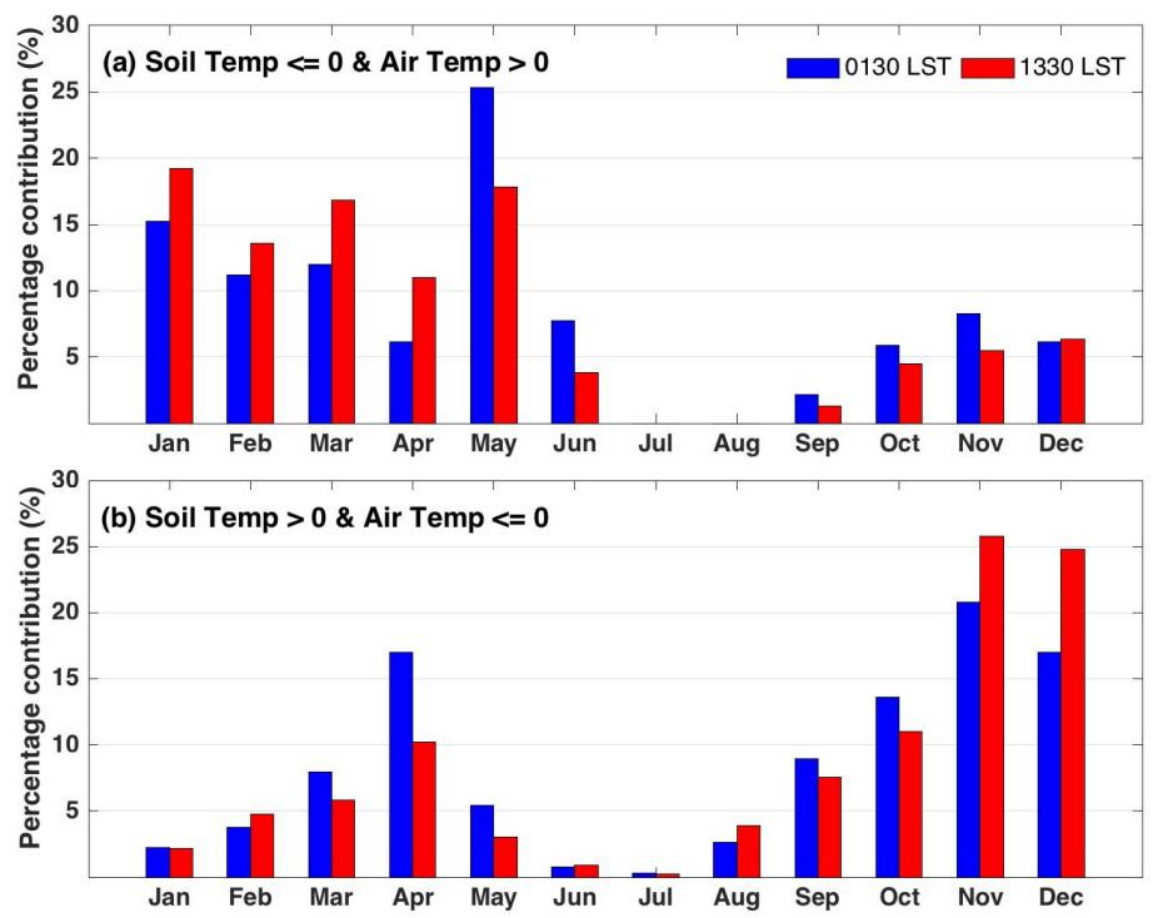

Fig. 5 Percentage contribution of each month in difference between air and soil temperatures under freeze and thaw cases. 

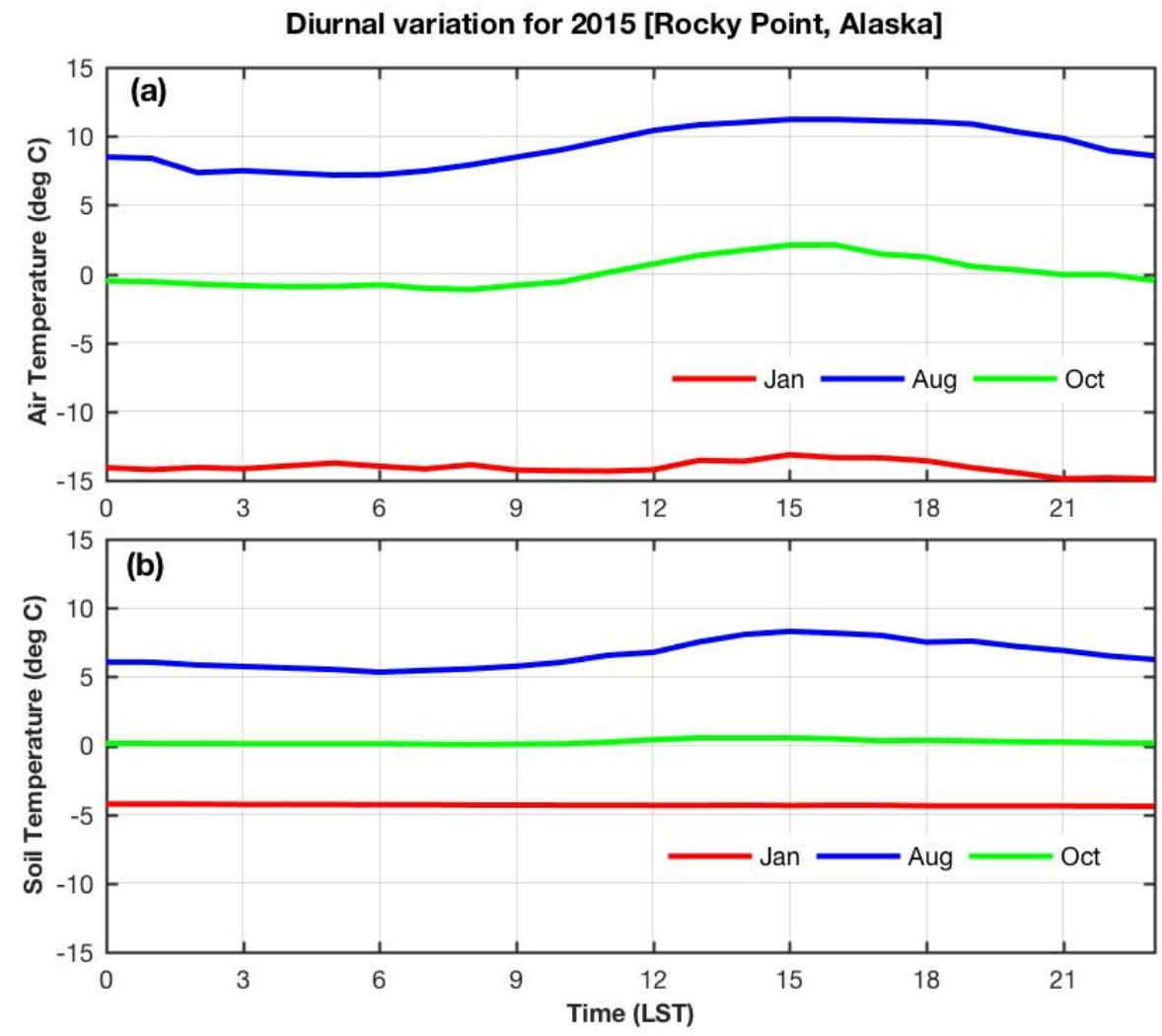

Fig. 6 Diurnal variations of (a) air temperature and (b) soil temperature for the month of January, August and October over a SNOTEL site during 2015. 


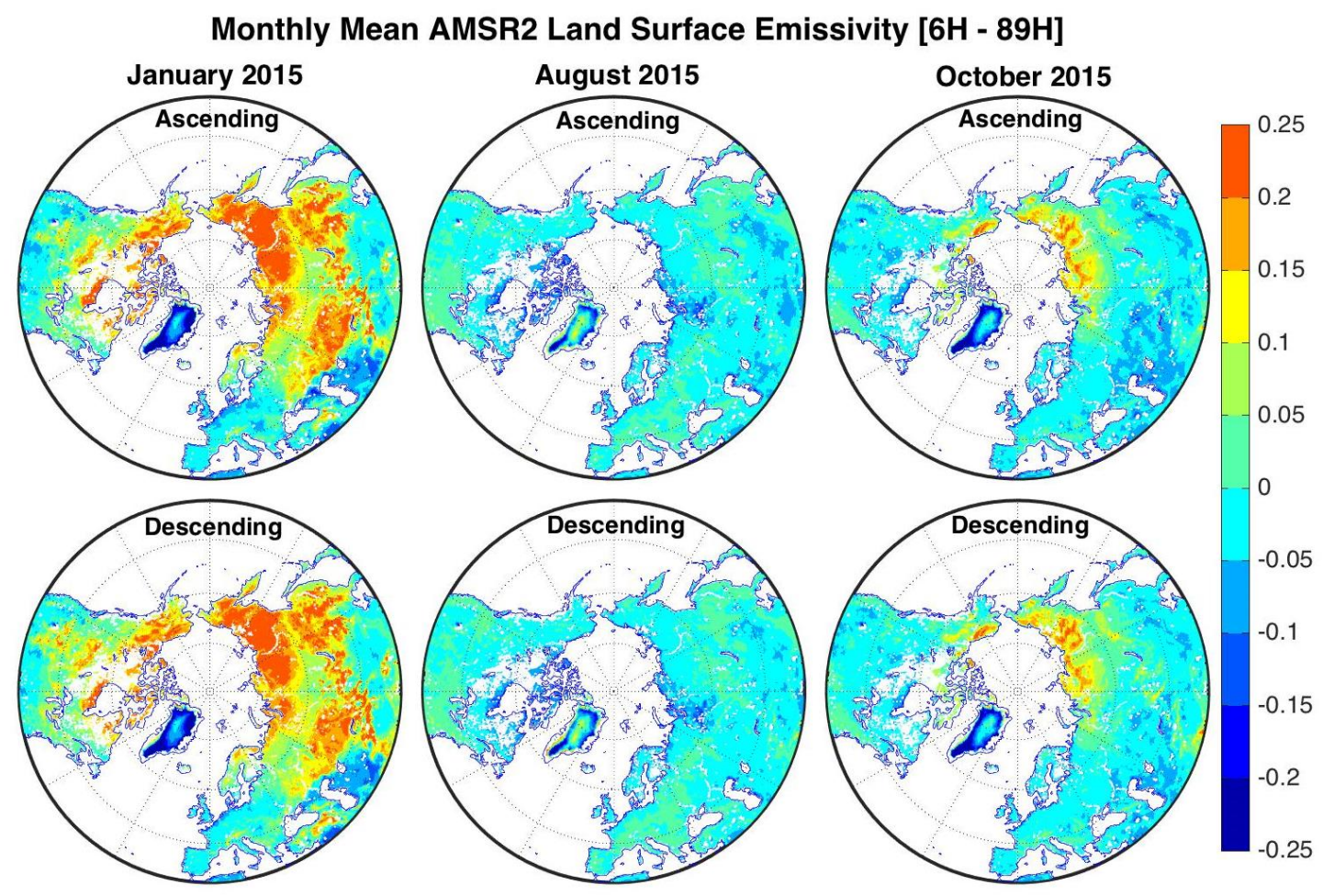

Fig. 7 Spatial distributions of AMSR2 land emissivity difference between $6 \mathrm{GHz}$ and 89 $\mathrm{GHz}$ at horizontal polarization for January, August, and October 2015.
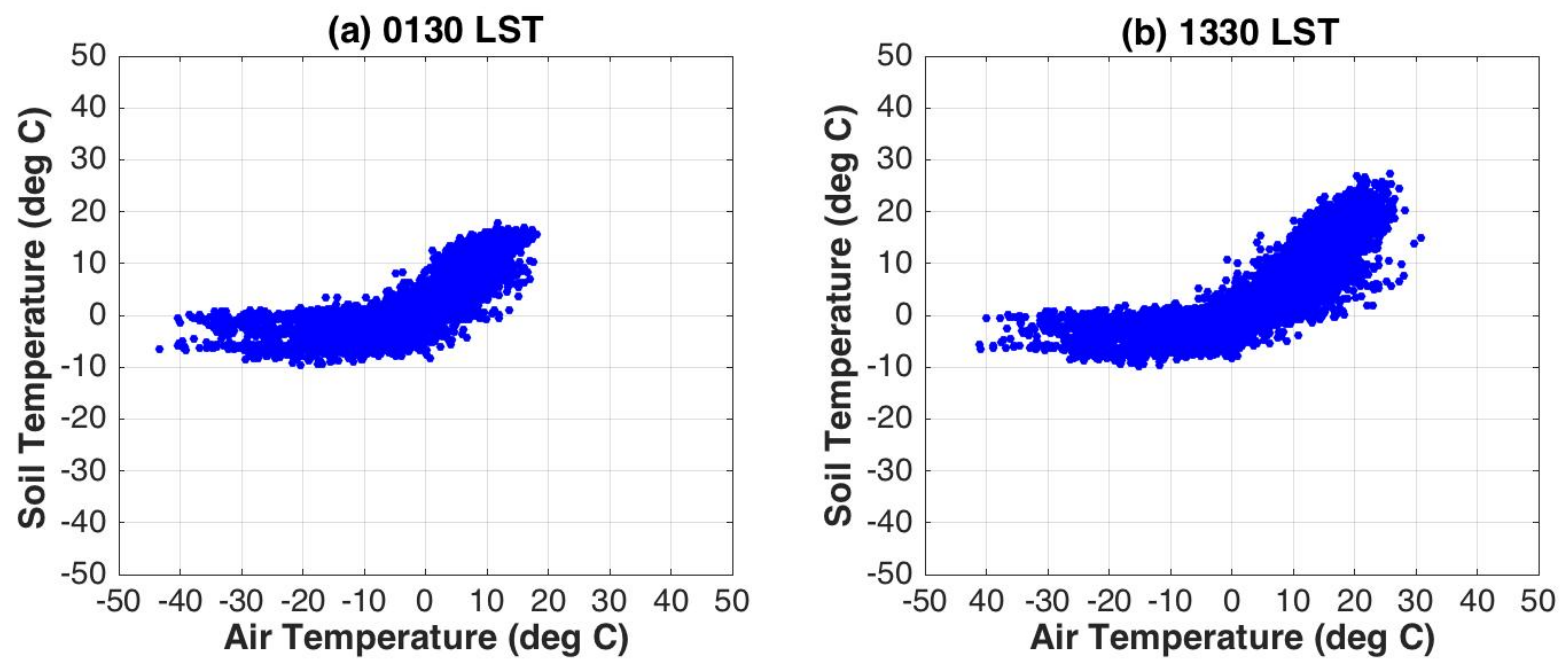

Fig. 8 Scatter plots between air temperature and soil temperature for the three-year period (2013-2015). 